\title{
The establishment of metrological characteristics of the method "Ethanol as Internal Standard" for the direct determination of volatile compounds in alcoholic products
}

\author{
Siarhei Charapitsa $\odot^{* 1}$, Svetlana Sytova $\odot^{1}$, Anton Korban $\odot^{1,2}$, \\ Nicolai Boyarin $\odot^{3}$, Inna Shestakovich $\odot^{3}$ and Radomír Čabala $\odot^{4}$ \\ ${ }^{1}$ Institute for Nuclear Problems of Belarusian State University, 220030, \\ Bobruyskaya Str., 11, Minsk, Belarus \\ ${ }^{2}$ Belarusian State University, 220030, Nezavisimosti avenue, 4, Minsk, Belarus \\ ${ }^{3}$ Republican Centre for Hygiene, Epidemiology and Public Health, 220099, \\ Kazintsa Str., 50, Minsk, Belarus \\ ${ }^{4}$ Faculty of Science of Charles University, Department of Analytical Chemistry, \\ Hlavova 2030/8, 128 40, Prague 2, Czech Republic
}

(Received February 09, 2018; Revised April 02, 2018; Accepted May 02, 2018)

\begin{abstract}
An extensive study concerning the problem of volatile compounds determination in alcoholic products by gas chromatography has been undertaken in the paper. A row of gravimetrically prepared standard solutions was analysed with three analytical methods: traditional method of internal standard, advanced method of internal standard and external standard method. The main analytical characteristics and metrological parameters of the "Ethanol as Internal Standard" method were compared with the traditional approaches. It was shown that this method leads to correct values of volatiles concentrations and the corresponding metrological characteristics are generally better.
\end{abstract}

Keywords: Alcoholic products; ethanol; gas chromatography; quantification; volatile compounds. (C) 2018 ACG Publications. All rights reserved.

\section{Introduction}

Alcoholic beverage consumption is almost everybody's concern. The fact is that alcoholic products are foodstuff therefore the quality control tests are of top priority. Apart from the usual overconsumption there is another risk factor which poses a threat to human health. It is the high content of

\footnotetext{
* Corresponding author E-Mail: svcharapitsa@tut.by 
volatile compounds which are by-products of alcoholic beverages manufacturing process and the simplest organic molecules of primary alcohols, esters and aldehydes.

There are a lot of types of alcoholic beverages with different volatiles concentrations and alcohol by volume (ABV) content. The detection of volatiles in various alcoholic beverages is often performed with gas chromatography (GC) method [1]. There is also a challenge of quantitative determination of volatile compounds, i.e. the expression of their contamination in $\mathrm{mg} / \mathrm{mg}, \mathrm{mg} / \mathrm{L}$ or $\mathrm{mg} / \mathrm{L}$ of absolute alcohol (AA) units. The quantity of determined volatiles differs from beverage to beverage, for instance from few compounds [2-5] to more than 30 [6-10].

Speaking about differences in ethanol content in analysed samples it should be said that GC method is used worldwide for analysing beverages with small ethanol content [11-12] as well as with great one [13]. It is also necessary to note that according to European Pharmacopeia volatile impurities determination in ethanol (100\% and 96\%) also proceeds with GC [14].

\section{Experimental}

\subsection{Analytical Methods}

The main goal of the current study was to demonstrate the features and advantages of three methods of quantitative analysis of alcohol-containing products in order to make a comparison between them. Gravimetrically prepared standard solutions were used as analysed samples.

The first method taken into account is internal standard (IS) method. In accordance with the Commission Regulation (EC) No 2870/2000 [15], the official methods of the Association of Official Analytical Chemists (AOAC) [16-17] and the official methods of the International Organization of Vine and Wine (OIV) [18] the quantitative determination of volatile compounds in alcoholic products is performed with IS method. It means the artificial addition of IS compound into both standard solution and testing sample. In our study 2-pentanol was used as an IS compound. Relative response factors (RRF) of $i$-th analysed compound relatively 2-pentanol were calculated according to the formula:

$$
R R F_{i}^{P n t}=\frac{C_{i}^{s t}}{A_{i}^{s t}} \cdot \frac{A_{P n t}^{s t}}{C_{P n t}^{s t}}
$$

where $A_{i}^{s t}$ and $A_{P n t}^{s t}$ are the values of detector response, for example, peak areas, for the $i$-th individual compound and 2-pentanol in standard solution, respectively; $C_{i}^{s t}$ and $C_{P n t}^{S t}$ are the concentrations of the $i$-th analysed compound and 2-pentanol, correspondingly, in $\mathrm{mg} / \mathrm{kg}$ units in standard solution. Then the obtained calibration coefficients were used for sample analysis:

$$
C_{i}=R R F_{i}^{P n t} \cdot \frac{A_{i}}{A_{P n t}} \cdot C_{P n t}
$$

where $C_{i}$ is the concentration of $i$-th analysed volatile in $\mathrm{mg} / \mathrm{kg}$ units; $C_{P n t}$ is the concentration of added 2-pentanol in $\mathrm{mg} / \mathrm{kg}$ units; $A_{i}$ and $A_{P n t}$ are the values of detector response for the $i$-th individual compound and 2-pentanol in analysed sample, respectively. The Eq. (2) slightly differs from the corresponding in [15], as internal standard compound was added in all standard solutions simultaneously with analysed compounds, so there was no need in coefficients which are responsible for dilution.

According to the above-mentioned regulatory documents volatiles concentrations must be finally expressed in $\mathrm{mg} / \mathrm{L}$ AA units. For this aim one should perform an ABV determination operation which lays in the density measurement and subsequent usage of international alcoholometric tables [19]. The presentation of concentration values of the examined compounds in the required $\mathrm{mg} / \mathrm{L}$ AA units is performed according to the following expression:

$$
C_{i}(m g / L A A)=\frac{C_{i}(m g / k g) \cdot \rho_{\text {sample }}}{A B V(v / v) \cdot 10^{6}}
$$


where $\rho_{\text {sample }}$ is the density of the test sample in $\mathrm{mg} / \mathrm{L}$ units. It should be noted that while testing alcohol-containing products with a noticeable content of volatile compounds (more than $800 \mathrm{mg} / \mathrm{L} \mathrm{AA}$ totally), the usage of international alcoholometric water-ethanol tables will never provide the required accuracy in determination of $\mathrm{ABV}(0.1 \%$ by volume $)$ since these tables can be used only for binary water-ethanol solutions. Thus, there is a so-called phenomenon of "real" and "apparent" strength. This problem and one of its possible solutions were pointed out in [20].

Apart from IS method there is another well-known method of external standard (ES). Its main idea lies in the plotting of the calibration curve according to the data obtained from the subsequent measurement of a single (several) standard solution. In case of using ES method the response factors (RF) play the role of calibration parameters. There is no necessity in IS compound addition while applying this method. Subsequently the value of concentration of $i$-th compound in the analysed sample is defined by the following expression:

$$
C_{i}=R F_{i} \cdot A_{i}=\frac{C_{i}^{s t}}{A_{i}^{s t}} \cdot A_{i}
$$

where the parameters $C_{i}^{s t}, A_{i}$ and $A_{i}^{s t}$ have the same meaning as in Eqs. (1-2).

Consequently the concentrations in $\mathrm{mg} / \mathrm{kg}$ or $\mathrm{mg} / \mathrm{L}$ units are determined. The conversion of obtained results into mg/L AA units proceeds as in the IS method. The ES method has its own application area, for instance, it was used in works $[9,11]$.

The last method taken into consideration is the method called "Ethanol as Internal Standard". It was proposed and discussed in publications [21-24] where its novel, innovative and up-to-date character was shown. The process of sample analysis is similar to that in the traditional IS method as RRFs are to be determined:

$$
R R F_{i}^{E t h}=\frac{C_{i}^{s t}}{A_{i}^{s t}} \cdot \frac{A_{E t h}^{s t}}{\rho_{E t h}}
$$

where $C_{i}^{s t}$ is a concentration of the $i$-th analysed compound in $\mathrm{mg} / \mathrm{L} \mathrm{AA}$ units ; $\rho_{E t h}=789300 \mathrm{mg} / \mathrm{L}$ is the ethanol density.

Oppositely to the generally adopted practices the advanced method uses the major volatile compound as the IS. As ethanol always presents in alcohol-containing products, there is no necessity in its artificial addition into analysed sample. Also its concentration in $\mathrm{mg} / \mathrm{L}$ AA units in every ethanol containing product is known with a $100 \%$ guarantee and is equal to ethanol density. So, this method eliminates the necessity of sample density measurement, as concentrations of volatiles in $\mathrm{mg} / \mathrm{L}$ AA units are determined directly from $\mathrm{GC}$ data:

$$
C_{i}(m g / L A A)=R R F_{i} \cdot \frac{A_{i}}{A_{E t h}} \cdot \rho_{E t h}
$$

Let us estimate the differences between uncertainties calculations for two IS methods. According to the guide [25] the total uncertainty of the method can be evaluated as the sum of uncertainties of its components. In our case these components are the values that are necessary for the calculation of volatiles concentrations in $\mathrm{mg} / \mathrm{L} \mathrm{AA}$ units. Thus, the formula for uncertainty calculation in case of the traditional internal standard method will include the uncertainties of all values from Eqs. (2) and (3):

$$
\frac{u\left(C_{i}\right)}{C_{i}}=\sqrt{\left(\frac{u\left(R R F_{i}\right)}{R R F_{i}}\right)^{2}+\left(\frac{u\left(A_{i}\right)}{A_{i}}\right)^{2}+\left(\frac{u\left(A_{I S}\right)}{A_{I S}}\right)^{2}+\left(\frac{u\left(C_{I S}\right)}{C_{I S}}\right)^{2}+\left(\frac{u\left(\rho_{\text {sample })}\right.}{\rho_{\text {sample }}}\right)^{2}+\left(\frac{u(A B V(v / v))}{A B V(\mathcal{V} / v)}\right)^{2}} .
$$

As "Ethanol as Internal Standard" method allows direct quantification of volatiles according to Eq. (6), the analogous formula will be written as follows: 


$$
\frac{u\left(C_{i}\right)}{C_{i}}=\sqrt{\left(\frac{u\left(R R F_{i}\right)}{R R F_{i}}\right)^{2}+\left(\frac{u\left(A_{i}\right)}{A_{i}}\right)^{2}+\left(\frac{u\left(A_{\text {Ethanol }}\right)}{A_{\text {Ethan }}}\right)^{2}} .
$$

It can be seen, that in these two formulas the first three terms under the square root have the same nature and the same order of magnitude. Also there are less additive components in Eq. (8) than in Eq. (7). These additional terms are responsible for the uncertainty in the determination of concentration of internal standard, density and ABV value of a test sample. The presence of these additional terms indicates a higher uncertainty during the determination of concentrations of volatile compounds by the traditional method than "Ethanol as Internal Standard" method.

\subsection{Metrological Tests}

Appropriate statistical tests should be applied to the received data sets in order to establish that one method is equivalent or better than the other. The Eurachem Guide [25] and series of ISO 5725 standards [26] were used as a theoretic base for metrological characteristics establishment. Inter-laboratory biases, repeatability limits and uncertainties were calculated for all prepared standard solutions except solution "WES-C" as it was used for calibration.

The value of limit of quantification (LOQ) appears to be the lowest level of volatile concentration at which the performance is acceptable for a typical application [25]. The determination of LOQ in GC method involves the measurement of standard solution with very low components concentrations that's why the "WES-3" solution was used for this aim (see Table 1). Firstly, the $s_{o}^{\prime}$ value was determined as a ratio of standard deviation to the root of number of replicates according to the following formula:

$$
s_{O}^{\prime}(m g / L A A)=\frac{s_{O}}{\sqrt{N}}=\frac{\sqrt{\frac{1}{N-1} \sum_{i=1}^{N}\left(x_{i}-\bar{x}\right)^{2}}}{\sqrt{N}},
$$

where $s_{0}$ is a standard deviation, $x_{i}$ is the value of concentration of a single measurement and $\bar{x}$ is the average value of concentration within $N$ measurements. Finally LOQs were calculated as $k_{Q} \cdot s_{o}^{\prime}$, where $k_{Q}$ was set to 10 [25].

Inter-laboratory biases were calculated for each analysed compound as a characteristic of method accuracy [25]. Bias values were determined by the following equation:

$$
\text { bias }, \%=\frac{\left|\bar{C}_{i}-C_{i}^{s t}\right|}{C_{i}^{s t}} \cdot 100 \% \text {, }
$$

where $\bar{C}_{i}$ is the average concentration value between laboratories.

Repeatability characterizes precision of the method as it shows the dispersion of the obtained values between each other. For within-laboratory evaluation of repeatability the relative standard deviations (RSD, \%) were calculated for each used method by traditional practices. Repeatability limits of $n$ measurements were calculated as $f \sqrt{n}$, where $f$ was set equal to 1.96 for $95 \%$ confidence level [26]. Repeatability limits describe inter-laboratory precision.

Uncertainty acts as one of the most important method's performance. Expanded uncertainties were calculated for inter-laboratory results as reproducibility standard deviation multiplied by coverage factor equal to 1.96 .

\subsection{Materials and Preparation}

All individual chemical compounds were purchased from Sigma-Aldrich (Berlin, Germany). Highpurity ethanol was purchased from JSC "Dyatlovo Wine and Distillery Plant Algon" (Belarus). All standard solutions were prepared gravimetrically by the addition of individual chemical compounds into water-ethanol solution. Initial water-ethanol solution with the ABV equal to $40 \%$ was prepared by the dilution of pure ethanol with deionized water. 


\subsection{Instrumental Analysis}

\subsubsection{Laboratory of Analytical Research (LAR)}

The samples were analysed using a Chromatec-Kristall 5000 gas chromatograph (JSC SDB Chromatec, Yoshkar-Ola, Russia) equipped with FID and an autosampler. Instrument control and data analysis were performed with UniChrom software (New Analytical Systems Ltd., Minsk, Belarus). The gas chromatograph was fitted with capillary column Rt-Wax, $60 \mathrm{~m} \times 0.53 \mathrm{~mm}$, with phase thickness of $1 \mu \mathrm{m}$ (Restek, Bellefonte, PA, USA). The oven temperature was the following: the initial isotherm at 75 ${ }^{\circ} \mathrm{C}$ for $9 \mathrm{~min}$ was raised to $130{ }^{\circ} \mathrm{C}$ at a rate of $5^{\circ} \mathrm{C} / \mathrm{min}$ then raised to $180{ }^{\circ} \mathrm{C}$ at a rate of $10{ }^{\circ} \mathrm{C} / \mathrm{min}$ with final isotherm of $155^{\circ} \mathrm{C}$ for $5 \mathrm{~min}$. The carrier gas was nitrogen ( $\geq 99.99 \%$ purity); the gas flow was 6.9 $\mathrm{mL} / \mathrm{min}$; the injector temperature was $160^{\circ} \mathrm{C}$; the detector temperature was $200^{\circ} \mathrm{C}$; the injector volume was $1 \mu \mathrm{L}$; the split ratio was 1:7. Split ratio was selected so that ethanol and propanol-2 could be separated by GC, where in case of smaller split ratio there is a risk of overlapping of these two peaks. Analytic balance OHAUS PA-214C with a precision of $0.2 \mathrm{mg}$ was used for gravimetric preparations.

\subsubsection{Laboratory of Republican Centre for Hygiene, Epidemiology and Public Health (RCH)}

The samples were analysed using an Agilent 6890 gas chromatograph (Agilent Technologies, Inc., USA) equipped with FID and an autosampler. Instrument control and data analysis were performed with GC ChemStation software chromatograph (Agilent Technologies, Inc., USA). The gas chromatograph was fitted with capillary column DB-Wax, $60 \mathrm{~m} \times 0.53 \mathrm{~mm}$ with phase thickness of $1 \mu \mathrm{m}$ (Agilent Technologies, Inc., USA). The oven temperature was the following: the initial isotherm at $65^{\circ} \mathrm{C}$ for 9 min was raised to $155^{\circ} \mathrm{C}$ at a rate of $7{ }^{\circ} \mathrm{C} / \mathrm{min}$ with final isotherm of $155^{\circ} \mathrm{C}$ for $2.6 \mathrm{~min}$. The carrier gas was hydrogen ( $\geq 99.99 \%$ purity); the gas flow was $2.7 \mathrm{~mL} / \mathrm{min}$; the injector temperature was $180{ }^{\circ} \mathrm{C}$; the detector temperature was $250^{\circ} \mathrm{C}$; the injector volume was $1 \mu \mathrm{L}$; the split ratio was $1: 10$.

\subsubsection{Laboratory of Faculty of Science of Charles University (CU)}

The samples were analysed using a Shimadzu GC 2010 gas chromatograph (Shimadzu Corporation, Inc., Japan) equipped with FID and a split/splitless injector. Instrument control and data analysis were performed with GC Solution software (Shimadzu, ver. 2.41). The gas chromatograph was fitted with capillary column Supelcowax 10,30 m $\times 0.25 \mathrm{~mm}$ with phase thickness of $0.5 \mu \mathrm{m}$ (Sigma Aldrich, Inc., USA). The oven temperature was the following: the initial isotherm at $30{ }^{\circ} \mathrm{C}$ for $5 \mathrm{~min}$ was raised to $100{ }^{\circ} \mathrm{C}$ at a rate of $5{ }^{\circ} \mathrm{C} / \mathrm{min}$ with final isotherm of $100{ }^{\circ} \mathrm{C}$ for $1 \mathrm{~min}$. The carrier gas was nitrogen ( $\geq 99.999 \%$ purity); the gas flow was $0.33 \mathrm{~mL} / \mathrm{min}$; the injector temperature was $280{ }^{\circ} \mathrm{C}$; the detector temperature was $280^{\circ} \mathrm{C}$; the injector volume was $1 \mu \mathrm{L}$; the split ratio was 1:50.

\subsection{Standard Solutions Preparation and Analysis}

Six standard water-ethanol (with $40 \% \mathrm{ABV}$ ) solutions were prepared gravimetrically according to ASTM D 4307 [27] recommendations by addition of individual chemical substances or solutions into initial water-ethanol mixture. The concentrations of volatile compounds in all prepared standard solution are presented in the Table 1. In calculations it was considered that the following impurities were presented in the initial ethanol (rectified ethyl alcohol): acetaldehyde (1.84 mg/L AA); methanol (17.57 $\mathrm{mg} / \mathrm{L} \mathrm{AA}$ ) and 2-propanol (1.15 mg/L AA).

All prepared standard solutions were measured by GC three times in each laboratory under repeatability conditions. The final concentration of each analysed compound considered to be the average value among three measurements. It was taken into consideration that standard solutions "WES3 " and "WES-A" were not measured in the CU laboratory. 
Table 1. The concentrations of compounds in prepared standard solutions.

\begin{tabular}{lcccccc}
\hline \multirow{2}{*}{ Compound/Solution } & \multicolumn{7}{c}{ Concentration, mg/L AA } \\
\cline { 2 - 7 } & WES-3 & WES-2 & WES-1 & WES-C & WES-B & WES-A \\
\hline acetaldehyde & $3.93 \pm 0.12$ & $11.0 \pm 0.33$ & $48.6 \pm 1.5$ & $223 \pm 4.5$ & $436 \pm 4.4$ & $4336 \pm 43$ \\
methyl acetate & $1.03 \pm 0.02$ & $9.74 \pm 0.19$ & $51.4 \pm 1.0$ & $242 \pm 4.8$ & $487 \pm 4.9$ & $5533 \pm 55$ \\
ethyl acetate & $1.11 \pm 0.02$ & $9.49 \pm 0.19$ & $49.7 \pm 1.0$ & $233 \pm 4.7$ & $476 \pm 4.8$ & $6813 \pm 68$ \\
methanol & $18.5 \pm 0.56$ & $27.7 \pm 0.83$ & $71.7 \pm 2.2$ & $271 \pm 5.4$ & $526 \pm 5.3$ & $5741 \pm 57$ \\
2-propanol & $2.75 \pm 0.08$ & $11.9 \pm 0.36$ & $55.6 \pm 1.7$ & $258 \pm 5.2$ & $512 \pm 5.1$ & $5774 \pm 58$ \\
ethanol (adv. IS) & 789300 & 789300 & 789300 & 789300 & 789300 & 789300 \\
1-propanol & $1.27 \pm 0.03$ & $10.7 \pm 0.21$ & $56.5 \pm 1.1$ & $265 \pm 5.3$ & $532 \pm 5.3$ & $6010 \pm 60$ \\
isobutyl alcohol & $1.45 \pm 0.03$ & $11.3 \pm 0.23$ & $58.9 \pm 1.2$ & $275 \pm 5.5$ & $553 \pm 5.5$ & $6214 \pm 62$ \\
2-pentanol (trad. IS) & $37.2 \pm 0.74$ & $75.8 \pm 1.52$ & $72.2 \pm 1.4$ & $70.0 \pm 1.4$ & $70.2 \pm 1.4$ & $91.6 \pm 1.8$ \\
1-butanol & $1.72 \pm 0.03$ & $11.0 \pm 0.22$ & $56.6 \pm 1.1$ & $264 \pm 5.3$ & $532 \pm 5.3$ & $5996 \pm 60$ \\
isoamyl alcohol & $1.95 \pm 0.04$ & $11.6 \pm 0.23$ & $59.2 \pm 1.2$ & $276 \pm 5.5$ & $556 \pm 5.6$ & $6244 \pm 62$ \\
\hline
\end{tabular}

\section{Results and discussion}

The calibration coefficients RRFs and RFs were calculated on the basis of the preparatory and triplicate measurement data of standard solution "WES-C", so it was a "single-point calibration" approach. The established calibration coefficients in a single laboratory are presented in the Table 2 . The others can be found in supporting materials (see Table 15). The typical chromatogram of standard solution "WES-C" is shown in the Figure 1 in logarithmic scale.

Table 2. The concentrations, average detector response and the calculated calibration coefficients for three analytical methods obtained in LAR for standard solution "WES-C".

\begin{tabular}{|c|c|c|c|c|c|c|c|}
\hline \multirow[b]{2}{*}{ Compound } & \multicolumn{3}{|c|}{ Concentration } & \multirow[b]{2}{*}{$\begin{array}{c}\text { Average } \\
\text { peak area, } \\
\mathrm{nA} \cdot \min \end{array}$} & \multicolumn{3}{|c|}{ Average calibration coefficient } \\
\hline & $\mathrm{mg} / \mathrm{kg}$ & $\mathrm{mg} / \mathrm{L} \mathrm{AA}$ & $\mathrm{mg} / \mathrm{L}$ & & $\begin{array}{l}\text { 2-pentanol } \\
\text { as IS }\end{array}$ & $\begin{array}{l}\text { Ethanol } \\
\text { as IS }\end{array}$ & $\begin{array}{l}\text { External } \\
\text { standard, } \\
\mathrm{mg} / \mathrm{L} \mathrm{AA} \cdot \\
\cdot(\mathrm{nA} \cdot \mathrm{min})^{-1}\end{array}$ \\
\hline acetaldehyde & 94.1 & 223 & 89.2 & 2.420 & 2.214 & 1.309 & 92.15 \\
\hline methyl acetate & 102 & 242 & 96.8 & 2.327 & 2.498 & 1.477 & 104.0 \\
\hline ethyl acetate & 98.3 & 233 & 93.2 & 3.060 & 1.829 & 1.082 & 76.15 \\
\hline methanol & 114 & 271 & 108 & 3.043 & 2.139 & 1.264 & 89.02 \\
\hline 2-propanol & 109 & 258 & 103 & 4.546 & 1.363 & 0.806 & 56.73 \\
\hline ethanol & 333038 & 789300 & 315720 & 11210 & 1.692 & 1.000 & 70.41 \\
\hline 1-propanol & 112 & 265 & 106 & 5.483 & 1.161 & 0.686 & 48.32 \\
\hline isobutyl alc. & 116 & 275 & 110 & 6.784 & 0.975 & 0.576 & 40.57 \\
\hline 2-pentanol & 29.5 & 70.0 & 28.0 & 1.682 & 1.000 & 0.591 & 41.62 \\
\hline 1-butanol & 112 & 264 & 106 & 6.041 & 1.051 & 0.621 & 43.76 \\
\hline isoamyl alc. & 117 & 276 & 111 & 6.837 & 0.971 & 0.574 & 40.42 \\
\hline
\end{tabular}




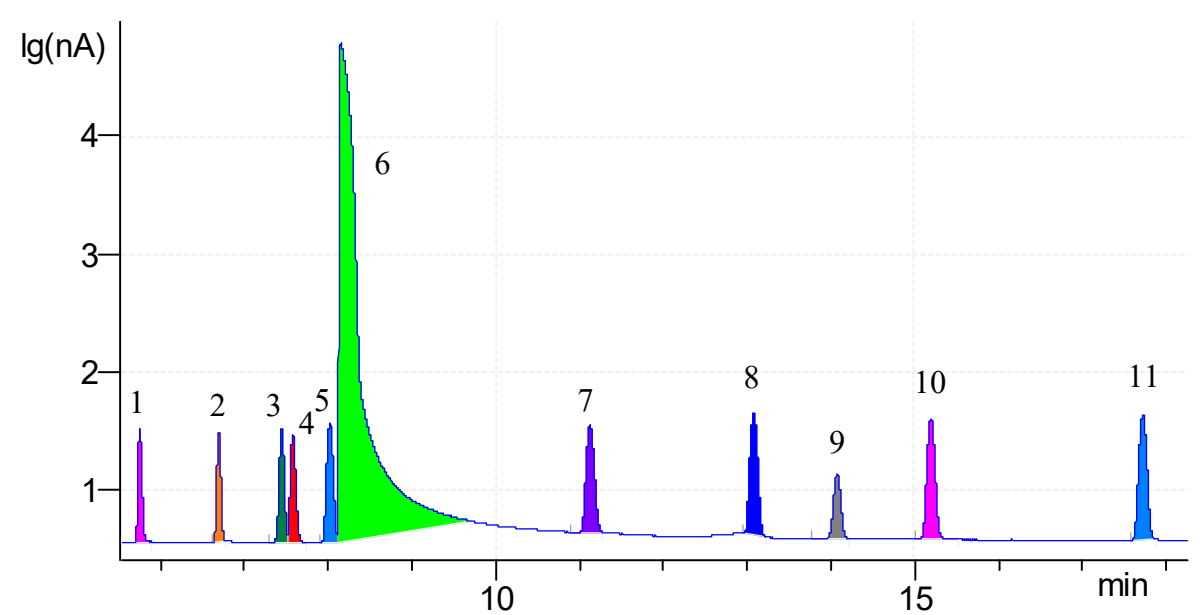

Figure 1. The typical chromatogram of standard solution "WES-C" obtained in LAR.

1 - acetaldehyde, 2 - methyl acetate, 3 - ethyl acetate, 4 - methanol, 5 - 2-propanol, 6 - ethanol, 7 - 1-propanol, 8 - isobutyl alcohol, 9 - 2-pentanol, 10 - 1-butanol, 11 - isoamyl alcohol.

Closed circular charts were chosen for the demonstration of obtained results as they allow to visualise great amount of data. Lower percentage characteristics of a method cause smaller area of a corresponding polygon so it becomes easy to compare the chosen methods. As the whole statistical report would include lots of charts only few of them are presented in this paper for the solution "WES1 " as an example. The others can be found in supporting materials in tabular forms (see Tables 16-18).

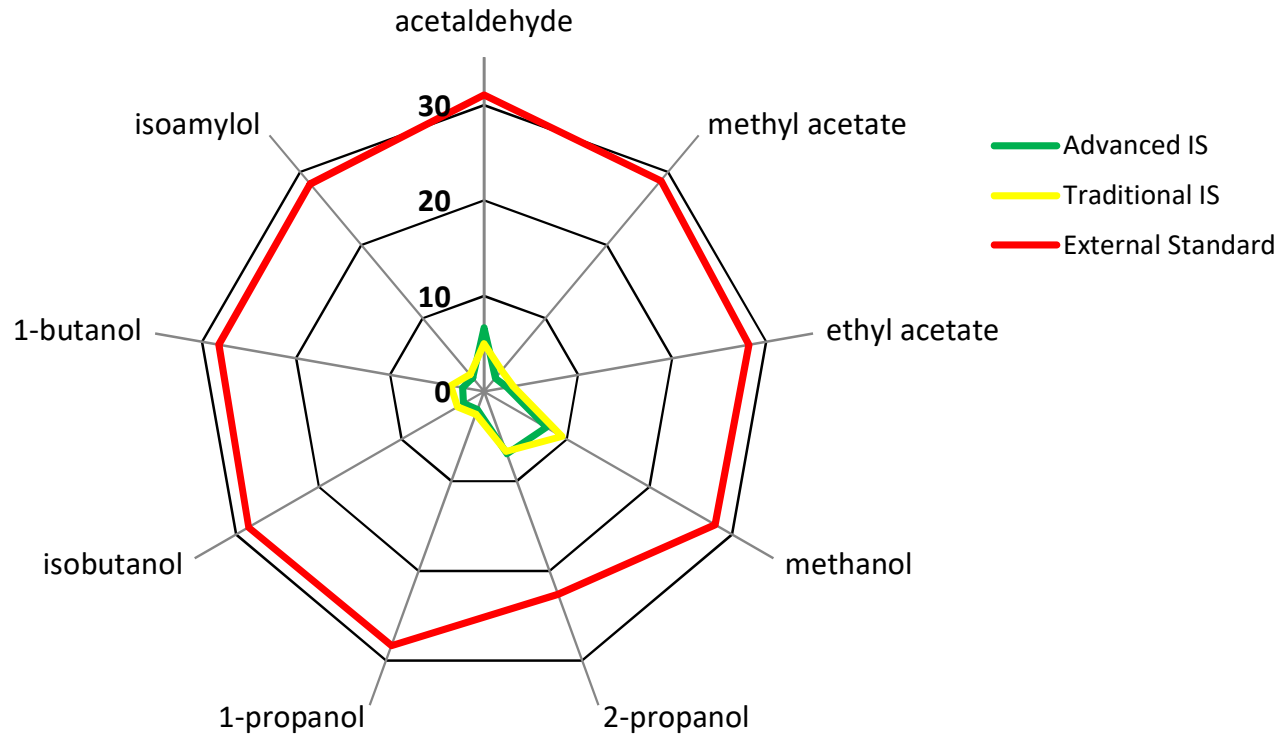

Figure 2. The histogram of repeatability limits (\%) comparison for the solution "WES-1"

Eventually in spite of different histograms shapes from various measurements the two IS methods showed better results and great similarity in characteristics values relatively to each other. Oppositely, ES method charts appeared to be much bigger than corresponding charts of the above mentioned IS methods. 


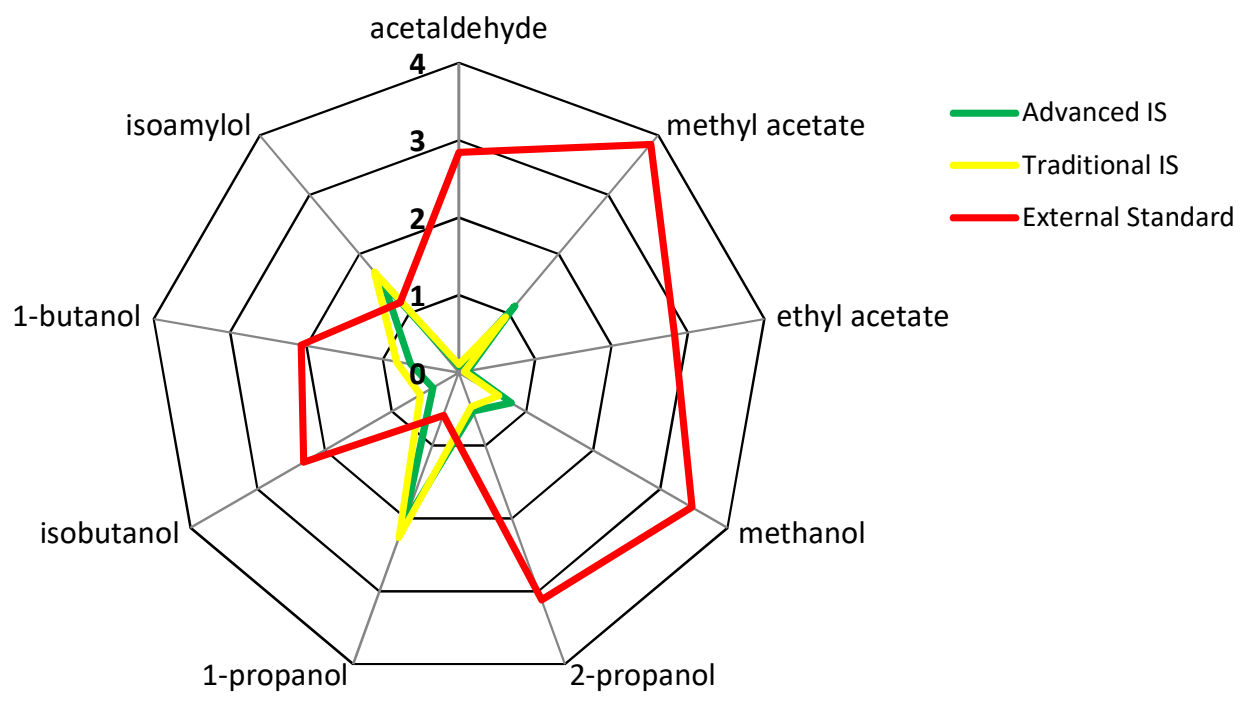

Figure 3. The histogram of biases (\%) comparison for the solution "WES-1"

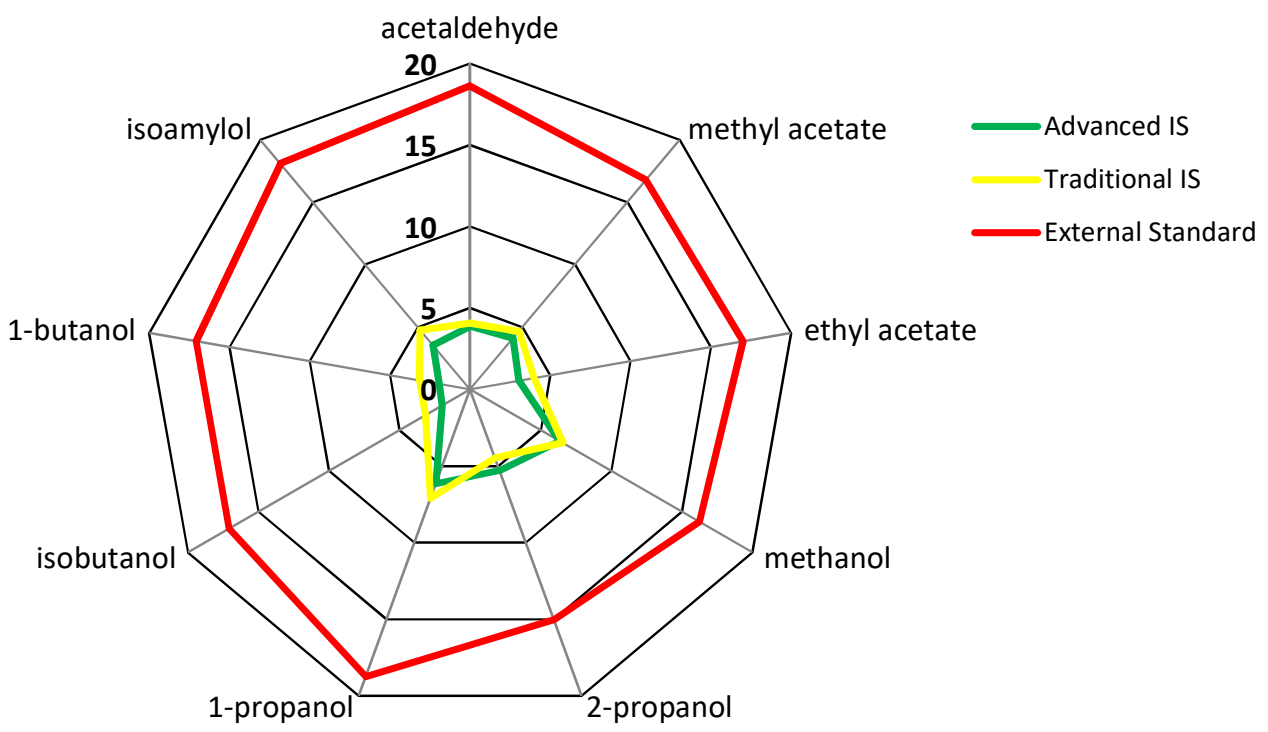

Figure 4. The histogram of the uncertainties (\%) comparison for the solution "WES-1"

The obtained LOQ values are presented in the Table 3. The great LOQ value for acetaldehyde in $\mathrm{CU}$ laboratory seems to be the result of incorrect storage conditions during transportation. Thus, acetaldehyde is the most sensitive component of all and it can be easily involved into chemical reactions of oxidation and ester formation even at room temperatures. Speaking about relative divergence in LOQ among methods it should be pointed out that the ES method generally lead to much higher values. This can characterize ES method as the worst method among all used under the represented conditions. The two IS methods showed very similar LOQ values in all laboratories, as expected. 2-propanol couldn't be separated at CU laboratory, that's why there is no data in corresponding cells. 
Table 3. Limits of quantification of the three analytical methods.

\begin{tabular}{|c|c|c|c|c|c|c|c|c|c|}
\hline \multirow{3}{*}{ Compound } & \multicolumn{9}{|c|}{ LOQ, mg/L AA } \\
\hline & \multicolumn{3}{|c|}{ LAR } & \multicolumn{3}{|c|}{$\mathrm{RCH}$} & \multicolumn{3}{|c|}{$\mathrm{CU}$} \\
\hline & $\begin{array}{c}\text { Trad } \\
\text { IS }\end{array}$ & $\begin{array}{c}\text { Novel } \\
\text { IS }\end{array}$ & ES & $\begin{array}{c}\text { Trad } \\
\text { IS }\end{array}$ & $\begin{array}{c}\text { Novel } \\
\text { IS }\end{array}$ & ES & $\begin{array}{c}\text { Trad } \\
\text { IS }\end{array}$ & $\begin{array}{c}\text { Novel } \\
\text { IS }\end{array}$ & ES \\
\hline acetaldehyde & 0.26 & 0.20 & 0.39 & 0.99 & 1.18 & 3.73 & 14.1 & 14.0 & 14.1 \\
\hline methyl acetate & 0.34 & 0.34 & 0.39 & 0.45 & 0.41 & 0.30 & 1.49 & 1.72 & 2.09 \\
\hline ethyl acetate & 0.17 & 0.18 & 0.21 & 0.21 & 0.27 & 0.98 & 1.33 & 1.02 & 0.92 \\
\hline methanol & 0.61 & 0.44 & 1.84 & 2.03 & 1.13 & 11.4 & 2.64 & 3.19 & 4.05 \\
\hline 2-propanol & 0.61 & 0.59 & 0.35 & 0.28 & 0.25 & 1.87 & N/A & N/A & N/A \\
\hline ethanol & - & - & - & - & - & - & - & - & - \\
\hline 1-propanol & 0.79 & 0.79 & 0.69 & 0.14 & 0.20 & 0.99 & 1.47 & 1.35 & 1.12 \\
\hline isobutyl alc. & 0.65 & 0.66 & 0.57 & 1.14 & 1.09 & 0.34 & 3.51 & 3.85 & 3.79 \\
\hline 2-pentanol & - & - & - & - & - & - & - & - & - \\
\hline 1-butanol & 1.39 & 1.39 & 1.22 & 0.83 & 0.78 & 1.04 & 1.79 & 1.85 & 2.39 \\
\hline isoamyl alc. & 2.12 & 2.12 & 1.85 & 0.44 & 0.55 & 1.81 & 0.76 & 1.03 & 1.36 \\
\hline
\end{tabular}

\section{Conclusions}

The analysis of obtained data shows that the advanced method "Ethanol as Internal Standard" is comparable with the traditional IS method from analytical point of view. It was showed that this method is robust and can be applied at a wide range of volatiles concentrations: from few $\mathrm{mg} / \mathrm{L}$ of AA to more than $5000 \mathrm{mg} / \mathrm{L}$ of AA. The calculated values of metrological characteristics obtained during the interlaboratory experimental tests show the great similarity between traditional and novel internal standard methods. Here the question about the possibility of using ethanol as IS compound can be answered positively. It was shown, that in spite of the fact that ethanol concentration is $10^{5}$ more than volatiles, modern GC systems allow to do correct quantification procedures.

In addition the "Ethanol as Internal Standard" method can be validated according to the interlaboratory test of prepared standard solutions as it was done in [15]. No more additional measurements and operations required except taking ethanol peak area into the calculations.

It should be also pointed out that method "Ethanol as IS" is the best from the traditional ones technically as there is no need to add IS compound in each analysed sample and measure the density of the sample in order to establish its $\mathrm{ABV}$ value. As a result the correct quantification of volatile compounds in alcoholic products becomes cheaper, faster and easier when the advanced method is applied.

\section{Acknowledgements}

The authors thank Lidziya Sabalenka for technical assistance.

\section{Supporting Information}

Supporting Information accompanies this paper on http://www.acgpubs.org/RNP

\section{ORCID}

Siarhei Charapitsa: 0000-0001-9657-1948

Svetlana Sytova: 0000-0002-2476-9979

Anton Korban: 0000-0002-2100-7709

Nicolai Boyarin: 0000-0001-6860-2241

Inna Shestakovich: 0000-0002-6259-8066

Radomír Čabala: $\underline{0000-0001-7022-1317}$ 


\section{References}

[1] M. Capobiango, E. S. Oliveira and Z. L. Cardeal (2013). Evaluation of methods used for the analysis of volatile organic compounds of sugarcane (Cachaça) and fruit spirits, Food Anal. Met. 6, 978-988.

[2] T. Osobamiro (2013). Analysis of some contaminants commonly found in alcoholic beverages, Am.Euras. J. Scien. Res., 8 (1), 53-56.

[3] R. Mapitse, H. Okatch and E. Moshoeshoe (2014). Analysis of volatile compounds in Khadi (an unrecorded alcohol beverage) from Botswana by gas chromatography-flame ionization detection (GC-FID), S. Afr. J. Chem., 67, 184 188.

[4] A. Jung, H. Jung, V. Auwärter, S. Pollak, A. M. Fárr, L. Hecser and A. Schiopu (2010). Volatile congeners in alcoholic beverages: analysis and forensic significance, Rom. J. Leg. Med., 18, 265-270.

[5] S. K. Tulashie (2017). Determination of methanol and ethanol concentrations in local and foreign alcoholic drinks and food products (Banku, Ga kenkey, Fante kenkey and Hausa koko) in Ghana, Int. J. Food Contamin. 4(14).

[6] R. Perestrelo, A. Fernandes, F. F. Albuquerque, J.C. Margues and J.S. Camara (2006). Analytical characterization of the aroma of Tinta Negra Mole red wine: Identification of the main odorants compounds, Anal. Chim. Acta 563, $154-164$.

[7] C. López-Vázquez, M. H. Bollaín, K. Berstsch and I. Orriols (2010). Fast determination of principal volatile compounds in distilled spirits, Food Control 21, 1436-1441.

[8] S. C. Dieguez, M. G. Pena and E. F. Gomez (2005). Volatile composition and sensory characters of commercial Galician Orujo spirits, J. Agric. Food Chem. 53, 6759-6765.

[9] A. G. Panosyan, G. V. Mamikonyan, M. Torosyan, E. S. Gabrielyan, S. A. Mkhitaryan, M. R. Tirakyan and A. Ovanesyan (2001). Determination of the composition of volatiles in Cognac (Brandy) by headspace gas chromatography-mass spectrometry, J. Anal. Chem. 10(56), 945-952.

[10] A. Leon-Rodriguez, L. Gonzalez-Hernandez, A. P. B. Rosa, P. Escalante-Minakata, and M.G. López (2006). Characterization of volatile compounds of Mezcal, an ethnic alcoholic beverage obtained from Agave salmiana, $J$. Agric. Food Chem. 54, 1337-1341.

[11] R.R. Mardrera and B.S. Valles (2007). Determination of volatile compounds in Cider spirits by gas chromatography with direct injection, J. Chromatog. Sci. 45, 428-434.

[12] G.-D. Dumitriu, N. L. Lerma, C.-I. Zamfir, Valeriu V. Coteaa and R.. Peinado. (2017). Volatile and phenolic composition of red wines subjected to aging in oak cask of different toast degree during two periods of time, $L W T$ Food Sci. Technol.86, 643-651.

[13] A. A. Apostolopoulou, A.I. Flouros and P.G. Demertzis, (2005). Differences in concentration of principal volatile constituents in traditional Greek distillates, Food Control 16, 157-164.

[14] European Pharmacopoeia (9th Edition) 2017. Ethanol (96\%), Ethanol, anhydrous, 2417-2420.

[15] Commission Regulation (EC) No 2870/2000 laying down Community reference methods for the analysis of spirits drinks. Official Journal of the European Communities.

[16] AOAC Official Methods 972.10. Alcohol (higher) and ethyl acetate in distilled liquors. Alternative gas chromatographic method. 2005. $1 \mathrm{p}$.

[17] AOAC Official Methods 972.11. Methanol in distilled liquors. Gas chromatographic method. 2005. 1 p.

[18] International Organization of Vine and Wine (OIV). Compendium of international methods of analysis of spirituous beverages of viti-vinicultural origin. Determination of the principal volatile substances of spirit drinks of vitivinicultural origin. OIV-MA-BS-14 : R2009. $12 \mathrm{p}$.

[19] International Organisation of Legal Metrology. International Alcoholometric Tables. Paris, 1972. 71 p.

[20] M. Stupak, V. Kocourek, I. Kolouchova and J. Hajslova (2017). Rapid approach for the determination of alcoholic strength and overall quality check of various spirit drinks and wines using GC-MS, Food Control 80, 307-313.

[21] S.V. Charapitsa, A. N. Kavalenka, N. V. Kulevich, N.M. Makoed, A. L. Mazanik, S. N. Sytova, N. I. Zayats, and Y. N. Kotov (2013). Direct determination of volatile compounds in spirit drinks by gas chromatography, J. Agric. Food Chem. 61, 2950-2956.

[22] S.V.Charapitsa, S.N. Sytova, A. A. Makhomet, T.I. Guguchkina, M.G. Markovsky, Y. F. Yakuba and Y. N. Kotov Method "Ethanol as Internal Standard" for determination of volatile compounds in Alcohol products by gas chromatography in daily practice, Cornell University Library: arXiv.org http://arxiv.org/abs/1601.05587 . 29 p.

[23] A. Korban and A. Makhomet (2016). Expansion of the new method "Ethanol as internal standard" for direct determination of volatile compounds in the spirit products, The proceedings of the 12th International Students Conference "Modern Analytical Chemistry", 49-55. 
[24] S. Charapitsa, S. Sytova, A. Korban, S. Vetokhin and N. Zayats (2017). Novel method for direct determination of the volatile compounds in alcohol products, The proceedings of the conference "Metrology - 2017", 234-238.

[25] B. Magnusson and U. Örnemark (eds.) Eurachem Guide: The Fitness for Purpose of Analytical Methods - A Laboratory Guide to Method Validation and Related Topics, (2nd ed. 2014).

[26] ISO 5725 Accuracy (trueness and precision) of measurement methods and results - Parts 1-6, ISO.

[27] ASTM D 4307-99. Standard Practice for Preparation of Liquid Blends for Use as Analytical Standards.

$$
\underset{\substack{\text { publications } \\ \text { (C) 2018 ACG Publications }}}{\mathrm{C}}
$$

